\title{
Cornual pregnancy in a non communicating horn of a bicornuate uterus: a case report
}

\author{
Satyajit Jena*, Amrita Nanda, Leesa Misra
}

Department of Obstetrics and Gynaecology, S.C.B. Medical College, Cuttack, Odisha, India

Received: 4 September 2013

Accepted: 21 September 2013

\section{*Correspondence:}

Dr. Satyajit Jena,

E-mail: dr_satyajit_jena@yahoo.co.in

(C) 2013 Jena S et al. This is an open-access article distributed under the terms of the Creative Commons Attribution Non-Commercial License, which permits unrestricted non-commercial use, distribution, and reproduction in any medium, provided the original work is properly cited.

\section{ABSTRACT}

An ectopic pregnancy is one in which the fertilised ovum is implanted and develop outside normal endometrial cavity. The most common localisation is tubal. We present the case of a patient found to have a cornual pregnancy diagnosed at 27 weeks of gestation.

Keywords: Bicornuate uterus, Non communicating horn, Ectopic pregnancy

\section{INTRODUCTION}

Cornual pregnancy is one of the most hazardous site for ectopic pregnancy. The diagnosis and management are challenging. They usually present late in gestation at 712 weeks because of myometrial distensibility. It frequently presents as a medical emergency as significant maternal haemorrhage and shock can result from cornual rupture due to abundant blood supply in this region from both uterine \& ovarian vessels.

\section{CASE REPORT}

A 24 year nulliparous female with positive pregnancy test presented as bleeding per vaginum and pain abdomen. On examination, uterus was 24 weeks size with tenderness, fetal heart sound was not localised, cervix was short, soft and os was closed. Initial Ultrasonography at 16 weeks of gestational age showed a single live intrauterine fetus. Another scan was advised and it showed an intrauterine dead fetus of average gestational age 18 weeks. Misoprostol tablets were given 6 hourly for 24 hours but it showed no response. Termination was the planned by intrauterine instillation of ethacridine lactate but it could not be done. Mechanical dilatation was done by Foleys catheter and following its expulsion oxytocin infusion was started but again it was of no value. Repeat scan was advised and it showed a cornual pregnancy in noncommunicating horn of uterus and Laparotomy was planned. On Laparotomy a female macerated abortus was delivered by giving incision over the lower segment of right cornua which was later confirmed to be noncommunicating and was resected. Right salpingectomy was done. Patient was discharged on $7^{\text {th }}$ postoperative day with advise for follow up after 6 weeks.

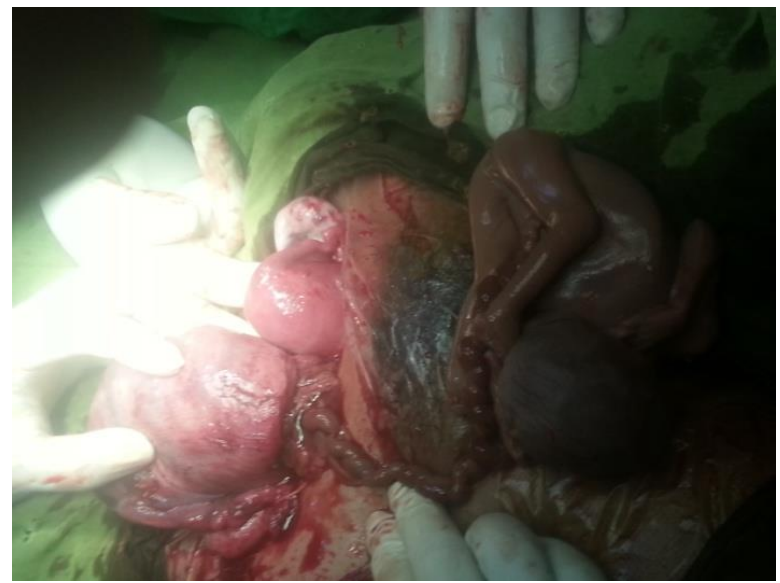

Figure 1: Dead fetus delivered by giving incision in the non communicating horn. 


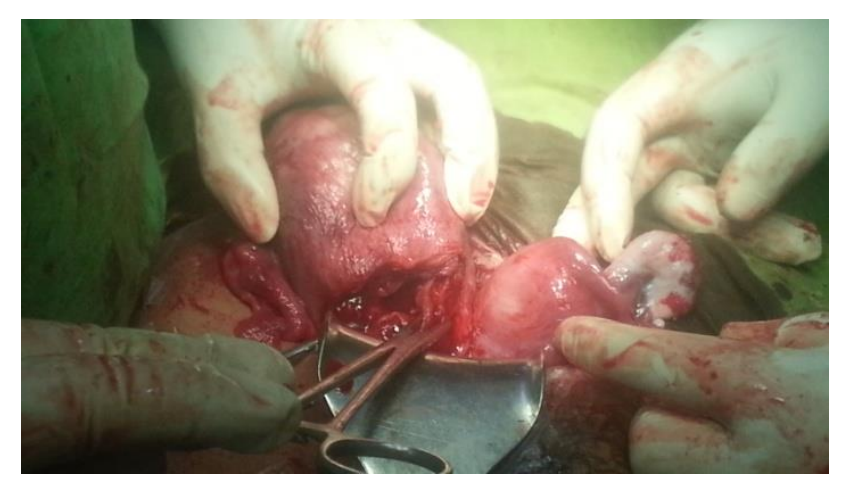

Figure 2: Bicornuate uterus after delivery of the fetus and placenta.

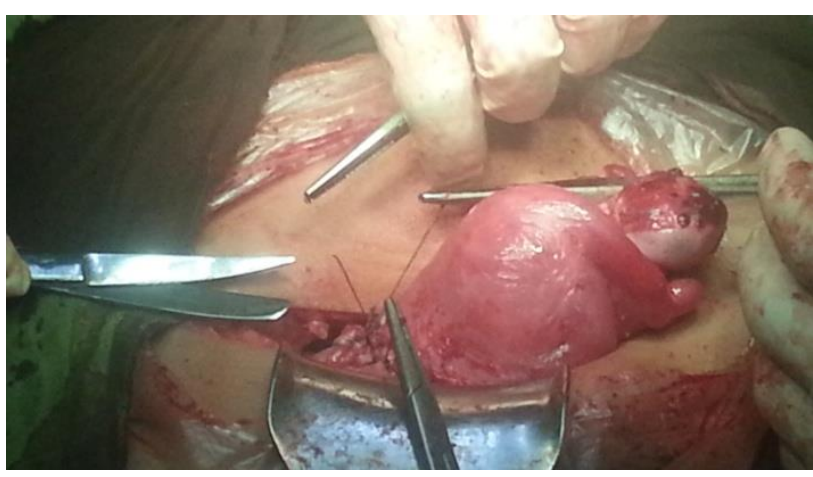

Figure 3: The non communicating horn was resected.

\section{DISCUSSION}

By definition, Cornual pregnancy refers to a pregnancy in the interstitial segment of a unicornuate or bicornuate uterus. ${ }^{1}$ This impregnation is presumed to occur by a spermatozoa which pass through normal half of uterus and tubes. It then fertilizes the ovum either in the peritoneal cavity or in the tube connected to the rudimentary horn. The concerned ovum is usually shed from the same side ovary as that of rudimentary horn. This can be diagnosed by transvaginal sonography. The traditional management of cornual pregnancy is by removal of the rudimentary horn and when the pedicle is short and the attachment is wide, hysterectomy may have to be done. ${ }^{2}$ There are successful reports of laparoscopic resection of cornual pregnancy. ${ }^{3-5}$ There are reports of success in treatment with single dose methotrexate, however there are also reports of failure. ${ }^{6,7}$

\section{CONCLUSION}

The diagnosis of cornual pregnancy can be at times very difficult which requires a high index of suspicion, careful ultrasonographic examination and at times laparoscopic evaluation. This can be managed by medical management, laparoscopic approach and Laparotomy depending on the patient's condition.

\section{REFERENCES}

1. Tulandi T, Al-Jaroudi D. Interstitial pregnancy: results generated from The Society of Reproductive Surgeons Registry. Obstet Gynecol 2004;103:47-50.

2. Katz D L. Barrett J P. Sanfilippo J S. Badway D M. Combined hysteroscopy and laparoscopy in the treatment of interstitial pregnancy. Am J Obstet Gynecol 2003; 188: 1113-1114.

3. Tulandi T, Vilos G, Gomel V. Laparoscopic treatment of interstitial pregnancy. Obstet Gynecol 1995; 85(3): 465-467.

4. Grobman W A. Milad M P. Conservative management of a large cornual ectopic pregnancy. Hum Reprod 1998; 13(7): 2002-2004.

5. Moon H S. Choi Y J. Park Y H. Kim S G. New simple endoscopic operations for interstitial pregnancies. Am J Obstet Gynecol 2000; 182: 114121.

6. Dilbaz S, Katas B, Demir B, Dilbaz B. Treating cornual ectopic pregnancy with a single methotrexate injection. J Reprod Med 2005; 50(2): 141-143.

7. Barnhart K, Spandorfer S, Coutifaris C. Medical treatment of interstitial pregnancy. A report of three unsuccessful cases. J Reprod Med 1997; 42: 521524.

DOI: 10.5455/2320-1770.ijrcog20131241

Cite this article as: Jena S, Nanda A, Misra L.

Cornual pregnancy in a non communicating horn of a bicornuate uterus: a case report. Int J Reprod Contracept Obstet Gynecol 2013;2:689-90. 